Research Paper

\title{
Impact of Polymorphisms in Casein Kinase 1 Epsilon and Environmental Factors in Oral Cancer Susceptibility
}

\author{
Shu-Hui Lin ${ }^{1,2}$, Mu-Kuan Chen³, Julia Hueimei Chang1, Bharath Kumar Velmurugan', Madhavi \\ Annamanedi ${ }^{5}$, Shih-Chi Su ${ }^{6}, \mathrm{Kun}^{-T u} \mathrm{Yeh}^{1,7,}$, , Shun-Fa Yang ${ }^{8,9,}$, \\ 1. Department of Surgical Pathology, Changhua Christian Hospital, Changhua, Taiwan \\ 2. Department of Medical Laboratory Science and Biotechnology, Central Taiwan University of Science and Technology, Taichung, Taiwan \\ 3. Department of Otorhinolaryngology-Head and Neck Surgery, Changhua Christian Hospital, Changhua, Taiwan \\ 4. Department of Biotechnology, Asia University, Taichung, Taiwan \\ 5. National Institute of Animal Biotechnology, Gachibowli, Hyderabad, India \\ 6. Whole-Genome Research Core Laboratory of Human Diseases, Chang Gung Memorial Hospital, Keelung, Taiwan \\ 7. School of Medicine, Chung Shan Medical University, Taichung, Taiwan \\ 8. Institute of Medicine, Chung Shan Medical University, Taichung, Taiwan \\ 9. Department of Medical Research, Chung Shan Medical University Hospital, Taichung, Taiwan
}

$\square$ Corresponding authors: Shun-Fa Yang, PhD. or Kun-Tu Yeh, MD, PhD. Institute of Medicine, Chung Shan Medical University, 110, Section 1, Chien-Kuo N. Road, Taichung, Taiwan, ROC. Fax: 886-4-24723229. E-mail: ysf@csmu.edu.tw (Shun-Fa Yang); 10159@cch.org.tw (Kun-Tu Yeh)

(C) The author(s). This is an open access article distributed under the terms of the Creative Commons Attribution License (https://creativecommons.org/licenses/by/4.0/). See http://ivyspring.com/terms for full terms and conditions.

Received: 2019.03.04; Accepted: 2019.08.05; Published: 2019.08.28

\begin{abstract}
In Taiwan, the incidence rate of oral cancer is constantly increasing. Polymorphisms and lifestyle habits are major contributing factors to the development of oral cancer in such cases. Casein kinase 1 epsilon $(C K I \varepsilon)$ gene expression plays a role in numerous cancers, and the knockdown of $C K I \varepsilon$ induces tumor cell-selective cytotoxicity. The present study was designed to determine the effects of $C K I \varepsilon$ gene polymorphisms combined with environmental carcinogens on susceptibility to developing oral squamous cell carcinoma and its clinicopathological status. Four single-nucleotide polymorphisms (SNPs) in CKIE gene (rs 135745, rs 135764, rs 1997644 and rs2075984) from 741 oral cancer patients and 462 healthy controls were analyzed using real-time polymerase chain reaction. Our results shown that variant types (GC) of CKI $\varepsilon$ polymorphic rs 135745 exhibited a significantly higher risk of 1.41 (95\% confidence interval [Cl]: 1.036-1.919) for oral cancer than did wild type alleles. Furthermore, these $C K l \varepsilon$ gene SNPs along with betel-quid chewing and/or tobacco use further increased susceptibility to oral cancer. Moreover, variant genotypes $(G C+C C)$ of $C K 1 \varepsilon$ rs 135745 were significantly associated with lymph node metastasis. These results suggested that the $C K I \varepsilon$ gene polymorphism is associated with the clinicopathological development of oral cancer and increases individuals' susceptibility to environmental carcinogens (e.g., smoking and betel-quid chewing) in terms of developing oral cancer.
\end{abstract}

Key words: Casein kinase 1 epsilon, oral cancer, polymorphism

\section{Introduction}

Oral cancer is estimated to be in the top 10 most common cancers worldwide, and is characterized by poor prognosis and late detection. Since 2003, oral cancer has been the fourth leading cause of cancer deaths among men in Taiwan [1]. The occurrence and growth of oral cancer depends on DNA sequence modifications known as single-nucleotide polymorphisms (SNPs). Along with genetic factors, environmental carcinogens associated with betel-quid (areca nut) chewing, tobacco use, and alcohol intake are major suggested causes of oral squamous cell carcinoma in Taiwan [2].

A member of the casein kinase I protein family, the casein kinase 1 epsilon (CK1ع) gene encodes serine/threonine protein kinase. Members of the CK1 gene family $(\alpha, \beta, \gamma 1, \gamma 2, \gamma 3$, and $\delta)$ have been shown 
to be involved in the regulation of cytoplasmic and nuclear processes as well as DNA replication and repair. Furthermore, studies have shown that in colon adenocarcinoma cells, human pancreatic cells, and salivary gland cancer cells, CK1 1 phosphorylates vital proteins of the Wnt signaling pathway to maintain cell division and tumor growth [3]. In our previous studies, we have demonstrated that decreased cytoplasmic CK1s expression correlates with low survival rates in patients with oral and hepatocellular carcinomas $[4,5]$. These results have suggested that CK1 $\varepsilon$ could be utilized as a prognostic predictor for oral and hepatocellular cancers and act as a tumor suppressor agent [5]. Mutations within the coding region of CK1ع were identified in several cancers, including ovarian, head and neck and breast cancers $[3,6]$. Relevant studies have reported that CK1 inhibitors may be drug candidates for treating alcoholism [7].

Gene polymorphisms and environmental factors combined determine individuals' susceptibility to oral cancer [8-13]. Identifying genetic factors and their SNPs associated with the development and progression of cancer are challenging tasks and are often used in early detection to determine the most effective treatment options $[14,15]$. To the best of our knowledge, this study is the first to target the CK1 $1 \varepsilon$ genetic polymorphism and compare it with environmental factors, such as betel-quid chewing, tobacco use, and alcohol consumption, to determine their effects on oral-cancer susceptibility in Taiwan.

\section{Materials and Methods}

\section{Subjects and specimen collection}

741 oral cancer patients who were recruited at Changhua Christian Hospital in Changhua and Chung Shan Medical University Hospital in Taichung, Taiwan between April, 2007 and April, 2013. Medical information of the oral cancer group, including the American Joint Committee on Cancer (AJCC) clinical stage, the tumor size, lymph node metastasis, distant metastasis and histologic grade, was obtained from their medical records. This study was approved by the Institutional Review Board of Changhua Christian Hospital (CCH No: 161224) and Chung Shan Medical University Hospital (CSMUH No: CS13214-1).

\section{Selection of casein kinase 1 epsilon Polymorphisms}

To obtain adequate power for evaluating the potential association, we investigated rs135745, rs135764, rs1997644 and rs2075984, those with minor allele frequencies greater than $5 \%$. Furthermore, these
SNPs of CK1 $1 \varepsilon$ gene were selected in this study since these SNPs were associated with the progression of the cancer $[16,17]$.

\section{DNA extraction and $C K I \varepsilon$ genotyping}

Genomic DNA was extracted using QIAamp DNA blood mini kits (Qiagen, Valencia, CA, USA) following the manufacturer's instructions as previously described [18, 19]. Allelic discrimination assessment for CK1e gene (rs135745, rs135764, rs1997644 and rs2075984) was performed using TaqMan assay with an ABI StepOnePlus ${ }^{\text {TM }}$ Software v2.3 real-time PCR system (Applied Biosystems, Foster City, CA, USA).

\section{Statistical analysis}

Multiple logistic regression models were used to analyze the association between CK1 $\varepsilon$ gene (rs135745, rs135764, rs1997644 and rs2075984) genotype frequencies, oral cancer risk and clinical characteristics after controlling for age, betel quid chewing, cigarette smoking, and alcohol consumption. The analyses were performed using the SPSS, and a $p$ value less than 0.05 was considered statistically significant.

\section{Results}

Demographical characteristics distribution is presented in Table 1. This study found a significant difference $(p<0.001)$ in the demographical distributions of age, smoking status, alcohol intake, and betel-quid chewing between the control subjects and oral cancer patients (Table 1).

The frequencies of genetic polymorphisms (rs135745, rs135764, rs1997644 and rs2075984) of the control group were in Hardy-Weinberg equilibrium. The people with the GC variants of the rs 135745 polymorphism had 1.41-fold (95\% CI: 1.036-1.919; $\mathrm{p}=$ 0.029 ) increased risk of developing oral cancer respectively to their corresponding WT gene (Table 2). However, no significant differences were observed between patients with oral cancer having rs135764, rs1997644 and rs2075984 polymorphisms of the CK1 $1 \varepsilon$ gene and those with the wild-type (WT) gene.

Tables 3 and 4 demonstrate the associations between environmental risk factors and genetic polymorphisms of $C K 1$. Among 821 smokers who had CK1E polymorphic rs135745, rs135764, rs1997644, or rs2075984 genes and who had a betel-quid chewing habit had 19.031- (95\% CI: 9.840-36.807; p < 0.001), 9.196- (95\% CI: 5.250-16.108; p < 0.001), 10.572- (95\% CI: 6.001-18.627; $\mathrm{p}<0.001)$ and 9.476-fold (95\% CI: 5.383-16.681; $\mathrm{p}<0.001$ ) higher risks of developing oral cancer, respectively, compared with individuals with the WT gene (Table 3). 
Table 1. Distributions of demographical characteristics in 462 controls and 741 male patients with oral cancer.

\begin{tabular}{|c|c|c|c|}
\hline Variable & Controls $(N=462)$ & Patients $(N=741)$ & $p$ value \\
\hline \multicolumn{4}{|l|}{ Age (yrs) } \\
\hline & $47.5 \pm 13.88$ & $54.5 \pm 11.13$ & $p<0.001^{*}$ \\
\hline \multicolumn{4}{|l|}{ Betel quid chewing } \\
\hline No & $375(81.2 \%)$ & $158(21.3 \%)$ & \\
\hline Yes & $87(18.8 \%)$ & $583(78.7 \%)$ & $p<0.001^{*}$ \\
\hline \multicolumn{4}{|l|}{ Cigarette smoking } \\
\hline No & $275(59.5 \%)$ & $107(14.4 \%)$ & \\
\hline Yes & $187(40.5 \%)$ & $634(85.6 \%)$ & $p<0.001^{*}$ \\
\hline \multicolumn{4}{|l|}{ Alcohol consumption } \\
\hline No & $309(66.9 \%)$ & $320(43.2 \%)$ & \\
\hline Yes & $153(33.1 \%)$ & $421(56.8 \%)$ & $p<0.001^{*}$ \\
\hline \multicolumn{4}{|l|}{ Stage } \\
\hline $\mathrm{I}+\mathrm{II}$ & & $349(47.1 \%)$ & \\
\hline $\mathrm{III}+\mathrm{IV}$ & & $392(52.9 \%)$ & \\
\hline \multicolumn{4}{|l|}{ Tumor T status } \\
\hline $\mathrm{T} 1+\mathrm{T} 2$ & & $408(55.1 \%)$ & \\
\hline $\mathrm{T} 3+\mathrm{T} 4$ & & $333(44.9 \%)$ & \\
\hline \multicolumn{4}{|l|}{ Lymph node status } \\
\hline No & & $492(66.4 \%)$ & \\
\hline $\mathrm{N} 1+\mathrm{N} 2+\mathrm{N} 3$ & & $249(33.6 \%)$ & \\
\hline \multicolumn{4}{|l|}{ Metastasis } \\
\hline M0 & & $732(98.8 \%)$ & \\
\hline M1 & & $9(1.2 \%)$ & \\
\hline \multicolumn{4}{|l|}{ Cell differentiation } \\
\hline Well differentiated & & $113(15.2 \%)$ & \\
\hline Moderately or poorly differentiated & & $628(84.8 \%)$ & \\
\hline
\end{tabular}

Table 2. The odds ratio (OR), adjusted OR (AOR), and $95 \%$ confidence interval $(\mathrm{Cl})$ of oral cancer associated with $\mathrm{CK} 1$ epsilon genotypic frequencies

\begin{tabular}{lllll}
\hline Variable & $\begin{array}{l}\text { Controls } \\
(\mathbf{N = 4 6 2 )}(\mathbf{\%})\end{array}$ & $\begin{array}{l}\text { Patients } \\
(\mathbf{N = 7 4 1 )}(\mathbf{\%})\end{array}$ & OR (95\% CI) & AOR (95\% CI) \\
\hline rs135745 & & & & \\
GG & $341(73.8 \%)$ & $497(67.1 \%)$ & Reference & Reference \\
GC & $111(24.0 \%)$ & $229(30.9 \%)$ & $1.39(1.052-1.834)^{*}$ & $1.41(1.036-1.919)^{*}$ \\
CC & $10(2.2 \%)$ & $15(2.0 \%)$ & $0.95(0.417-2.171)$ & $0.85(0.331-2.197)$ \\
GC+CC & $121(26.2 \%)$ & $243(32.8 \%)$ & $1.32(1.010-1.724)^{*}$ & $1.34(0.992-1.799)$ \\
rs135764 & & & & \\
GG & $331(71.6 \%)$ & $532(71.8 \%)$ & Reference & Reference \\
GA & $123(26.6 \%)$ & $190(25.6 \%)$ & $0.93(0.679-1.278)$ & $0.98(0.692-1.400)$ \\
AA & $8(1.7 \%)$ & $19(2.6 \%)$ & $1.45(0.577-3.665)$ & $1.80(0.671-4.832)$ \\
GA+AA & $131(28.3 \%)$ & $209(28.2 \%)$ & $0.94(0.698-1.274)$ & $1.03(0.739-1.444)$ \\
rs1997644 & & & & \\
GG & $187(40.5 \%)$ & $322(43.5 \%)$ & Reference & Reference \\
GA & $221(47.8 \%)$ & $327(44.1 \%)$ & $0.84(0.652-1.083)$ & $0.85(0.640-1.130)$ \\
AA & $54(11.7 \%)$ & $92(12.4 \%)$ & $1.02(0.689-1.520)$ & $0.90(0.574-1.398)$ \\
GA+AA & $275(59.5 \%)$ & $419(56.5 \%)$ & $0.88(0.691-1.118)$ & $0.87(0.664-1.137)$ \\
rs2075984 & & & & \\
AA & $159(34.4 \%)$ & $246(33.2 \%)$ & Reference & Reference \\
AC & $221(47.8 \%)$ & $371(50.1 \%)$ & $1.19(0.880-1.621)$ & $1.13(0.802-1.580)$ \\
CC & $82(17.8 \%)$ & $124(16.7 \%)$ & $0.98(0.694-1.377)$ & $1.13(0.676-1.885)$ \\
AC+CC & $303(65.6 \%)$ & $495(66.8 \%)$ & $1.17(0.864-1.579)$ & $1.13(0.805-1.573)$ \\
\hline
\end{tabular}

The OR with its $95 \%$ CI was estimated by logistic regression models.

The AOR with its $95 \%$ CI was estimated by multiple logistic regression models after controlling for age, betel quid chewing, cigarette smoking, and alcohol consumption.

${ }^{*} p<0.05$.

To clarify the role of CK1E genetic polymorphisms in oral cancer clinical statuses, such as tumor size, lymph node or distant metastasis, and histological grade, the distribution frequency of clinical statuses and $C K 1 \varepsilon$ genotype frequencies in patients with oral cancer were estimated. As sown in
Table 4, we found that patients with the CK1E rs135745 variant genotypes $(\mathrm{GC}+\mathrm{CC})$ were significantly associated with lymph-node metastasis (1.622; 95\% CI: 1.037-2.536; $\mathrm{p}=0.034)($ Table 4).

Table 3. Associations of the combined effect of CKI epsilon gene polymorphisms and betel nut chewing with the susceptibility to oral cancer among 821 smokers.

\begin{tabular}{|c|c|c|c|c|}
\hline Variable & $\begin{array}{l}\text { Controls } \\
(\mathrm{N}=187)(\%)\end{array}$ & $\begin{array}{l}\text { Patients } \\
(\mathrm{N}=634)(\%)\end{array}$ & OR (95\% CI) & $\operatorname{AOR}(95 \% \mathrm{CI})$ \\
\hline \multicolumn{5}{|l|}{ rs135745 } \\
\hline $\begin{array}{l}\text { GG genotype and } \\
\text { non betel-nut } \\
\text { chewing }\end{array}$ & $87(46.5 \%)$ & $58(9.1 \%)$ & Reference & Reference \\
\hline $\begin{array}{l}\text { GC or CC genotype } \\
\text { or betel-nut chewing }\end{array}$ & $87(46.5 \%)$ & $393(62.0 \%)$ & $\begin{array}{l}6.776 \\
(4.518-10.163)\end{array}$ & $\begin{array}{l}6.150 \\
(4.069-9.296)\end{array}$ \\
\hline $\begin{array}{l}\text { GC or CC genotype } \\
\text { with betel-nut } \\
\text { chewing }\end{array}$ & $13(7.0 \%)$ & $183(28.9 \%)$ & $\begin{array}{l}21.115 \\
(10.986-40.583)\end{array}$ & $\begin{array}{l}19.031 \\
(9.840-36.807)\end{array}$ \\
\hline
\end{tabular}

rs135764

GG genotype and $\quad 84(44.9 \%) \quad 60(9.5 \%) \quad$ Reference $\quad$ Reference non betel-nut chewing

GA or AA genotype $80(42.8 \%) \quad 422(66.6 \%) \quad 7.385 \quad 6.988$ $\begin{array}{llll}\text { or betel-nut chewing } & (4.908-11.111) & (4.597-10.621)\end{array}$ GA or AA genotype $23(12.3 \%) \quad 152(24.0 \%) \quad 9.252 \quad 9.196$ with betel-nut $\quad(5.340-16.030) \quad(5.250-16.108)$ chewing

\section{rs1997644}

GG genotype and $\quad 47(25.1 \%) \quad 31(4.9 \%) \quad$ Reference Reference non betel-nut chewing

GA or AA genotype $96(51.3 \%) \quad 287(45.3 \%) \quad 4.533 \quad 4.366$ or betel-nut chewing $\quad(2.725-7.540)$

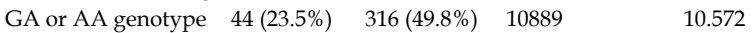
with betel-nut (6.267-18.917) (6.001-18.627) chewing

rs2075984

AA genotype and $\quad 42(22.5 \%) \quad 32(5.0 \%) \quad$ Reference Reference non betel-nut

chewing

AC or CC genotype $99(52.9 \%) \quad 238(37.5 \%) \quad 3.155 \quad 2.990$ or betel-nut chewing $\quad(0.1883-5.287) \quad(1.759-5.080)$ $\begin{array}{lllll}\text { AC or CC genotype } & 46(24.6 \%) & 364(57.4 \%) & 10.386 & 9.476\end{array}$ with betel-nut (5.975-18.052) (5.383-16.681) chewing

The adjusted odds ratio (OR; AOR) with its $95 \%$ confidence interval (CI) was estimated by multiple logistic regression models after controlling for age and alcohol consumption.

\section{Discussion}

Oral cancer in Taiwan is increasing at an alarming rate compared with other countries, which might be because of the alcohol consumption, tobacco use, and betel-quid chewing habits of the Taiwanese $[14,15,20]$. SNPs in genes, which regulate major pathways in the cells, are associated with greater susceptibility to oral cancer [21]. In this study, we determined the SNPs in the CK1 $1 \varepsilon$ gene are associated with clinicopathological statuses of oral cancer. CK1ع is a serine/threonine-specific phosphotransferase that controls major cellular pathways [22]. CK1ع expression was correlated with the $c-M Y C$ oncogene in colon, lung, and breast cancer tumors [23]. Varghese et al., reported that $\mathrm{CK} 1 \varepsilon$ expression is 
associated with glioblastoma cell survival [24]. Gene expression analysis data showed that $\mathrm{CK} 1 \varepsilon$ is overexpressed in several cancer tissue samples compared with in normal tissues. Furthermore, knockdown of CK1ع induces tumor cell-selective cytotoxicity [25].

Table 4. Distribution frequency of clinical status and CKI epsilon rs 135745 genotype frequencies in 741 patients with oral cancer.

\begin{tabular}{|c|c|c|c|c|}
\hline Variable & $\begin{array}{l}\text { GG (N = } \\
497) n(\%)\end{array}$ & $\begin{array}{l}\text { GC + CC (N } \\
=244) n(\%)\end{array}$ & OR $(95 \%$ CI) & AOR $(95 \%$ CI) \\
\hline \multicolumn{5}{|l|}{ Stage } \\
\hline $\mathrm{I} / \mathrm{II}$ & $238(47.9 \%)$ & $111(45.5 \%)$ & Reference & Reference \\
\hline III//IV & $259(52.1 \%)$ & $133(54.5 \%)$ & 0.795 (0.480-1.629) & $\begin{array}{l}0.796 \\
(0.481-1.319)\end{array}$ \\
\hline \multicolumn{5}{|l|}{ T classification } \\
\hline $\mathrm{T} 1 / \mathrm{T} 2$ & $274(55.1 \%)$ & $134(54.9 \%)$ & Reference & Reference \\
\hline $\mathrm{T} 3 / \mathrm{T} 4$ & $223(44.9 \%)$ & $110(45.1 \%)$ & $1.082(0.732-1.600)$ & $\begin{array}{l}1.081 \\
(0.731-1.598)\end{array}$ \\
\hline \multicolumn{5}{|l|}{$\begin{array}{l}\text { Lymph node } \\
\text { metastasis }\end{array}$} \\
\hline No & $342(68.8 \%)$ & $150(61.5 \%)$ & Reference & Reference \\
\hline Yes & $155(31.2 \%)$ & $94(38.5 \%)$ & $\begin{array}{l}1.623 \\
(1.038-2.537)^{*}\end{array}$ & $\begin{array}{l}1.622 \\
(1.037-2.536)^{*}\end{array}$ \\
\hline \multicolumn{5}{|c|}{ Distant metastasis } \\
\hline No & $490(98.6 \%)$ & $242(99.2 \%)$ & Reference & Reference \\
\hline Yes & $7(1.4 \%)$ & $2(0.8 \%)$ & $0.458(0.093-2.259)$ & $\begin{array}{l}0.461 \\
(0.093-2.277)\end{array}$ \\
\hline \multicolumn{5}{|c|}{ Histological grade } \\
\hline Well & $78(15.7 \%)$ & $35(14.3 \%)$ & Reference & Reference \\
\hline Moderate/Poor & $419(84.3 \%)$ & $209(85.7 \%)$ & 1.052(0.679-1.629) & $\begin{array}{l}1.055 \\
(0.995-1.007)\end{array}$ \\
\hline $\begin{array}{l}\text { The OR with its } \\
\text { The AOR with it } \\
\text { controlling for ag } \\
\text { consumption. } \\
\text { * } p<0.05 \text {. }\end{array}$ & $\begin{array}{l}\% \text { CI was esti } \\
5 \% \text { CI was es } \\
\text { betel quid ch }\end{array}$ & $\begin{array}{l}\text { mated by logis } \\
\text { imated by mu } \\
\text { ewing, cigaret }\end{array}$ & $\begin{array}{l}\text { ic regression models } \\
\text { tiple logistic regressi } \\
\text { e smoking, and alcol }\end{array}$ & $\begin{array}{l}\text { s. } \\
\text { ion models after } \\
\text { hol }\end{array}$ \\
\hline
\end{tabular}

In our study, a significant difference was found in demographical distributions of age, smoking status, alcohol intake, and betel-quid chewing between control subjects and oral cancer patients, which have also been observed in most relevant studies. We investigated the rs135745, rs1997644, rs2075984, and rs135764 polymorphisms of the CK1E gene. Our results showed that oral cancer patients with the rs135745 polymorphism of CK1e gene increased the risk of developing oral cancer. Hsu's group reported that even in the same cancer, $\mathrm{CK} 1 \varepsilon$ seems to exhibits diverse functions; thus, it could be an onco-protein or a tumor suppressor [26]. We further tested clinicopathological statuses, such as $\mathrm{T}$ classification, lymph-node metastasis, distant metastasis, histologic grade, and AJCC cancer stage, and observed significant lymph-node metastases in oral cancer patients with the rs135745-CK1E polymorphic gene. Future studies should investigate the mechanism by which these SNPs modify the clinicopathological status of oral cancer.

Individuals exposed to environmental carcinogens have increased risks of oral cancer [27]. Studies have stated that SNPs and oral cancer-associated environmental risk factors have a synergetic effect that can influence oral-cancer development [28]. The synergistic effects of environmental factors, betel-quid chewing, smoking, and the four CK1ع gene SNPs (rs135745, rs135764, rs1997644 and rs2075984) on the risk of oral cancer were studied. Mutations and changes in the expression and/or activity of CK1 isoforms are often identified in various cancers, such as ovarian and breast cancer as well as adenocarcinoma of the

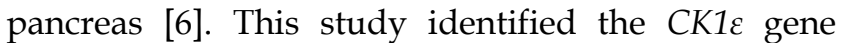
polymorphisms in oral cancer. However, the detailed mechanism of the CK1 $1 \varepsilon$ genetic polymorphism to oral cancer remained unclear. In the future, some studies are required to elucidate the mechanisms of $C K 1 \varepsilon$ genetic polymorphisms in oral cancer progression.

In conclusion, our results suggested that the CK1ع-rs135745 G/C gene polymorphism significantly increased the risk of oral cancer, and furthermore, the combined effects of CK1 1 gene polymorphisms with environmental risk factors increased sensitivity to oral cancer.

\section{Acknowledgments}

This study was supported by grants from Ministry of Science and Technology, Taiwan (MOST-106-2320-B-371-001) and Changhua Christian Hospital, Taiwan (108-CCH-IRP-044).

\section{Competing Interests}

The authors have declared that no competing interest exists.

\section{References}

[1] Chung TT, Pan MS, Kuo CL, Wong RH, Lin CW, Chen MK, et al. Impact of RECK gene polymorphisms and environmental factors on oral cancer susceptibility and clinicopathologic characteristics in Taiwan. Carcinogenesis 2011; 32: 1063-1068.

[2] Biolchini F, Pollastri G, Figurelli S, Chiarini L. Carcinogen metabolism, DNA damage repair and oral head and neck squamocellular carcinoma (HNSCC). A review. Minerva Stomatol 2005; 54: 405-414.

[3] Rodriguez N, Yang J, Hasselblatt K, Liu S, Zhou Y, Rauh-Hain JA, et al. Casein kinase I epsilon interacts with mitochondrial proteins for the growth and survival of human ovarian cancer cells. EMBO Mol Med 2012; 4: 952-963.

[4] Lin SH, Lin YM, Yeh CM, Chen CJ, Chen MW, Hung HF, et al. Casein kinase 1 epsilon expression predicts poorer prognosis in low T-stage oral cancer patients. Int J Mol Sci 2014; 15: 2876-2891.

[5] Lin SH, Yeh CM, Hsieh MJ, Lin YM, Chen MW, Chen CJ, et al. Low cytoplasmic casein kinase 1 epsilon expression predicts poor prognosis in patients with hepatocellular carcinoma. Tumour Biol 2016; 37: 3997-4005.

[6] Knippschild U, Kruger M, Richter J, Xu P, Garcia-Reyes B, Peifer C, et al. The CK1 Family: Contribution to Cellular Stress Response and Its Role in Carcinogenesis. Front Oncol 2014; 4: 96.

[7] Perreau-Lenz S, Vengeliene V, Noori HR, Merlo-Pich EV, Corsi MA, Corti C, et al. Inhibition of the casein-kinase-1-epsilon/delta/ prevents relapse-like alcohol drinking. Neuropsychopharmacology 2012; 37: 2121-2131.

[8] Su SC, Hsieh MJ, Lin CW, Chuang CY, Liu YF, Yeh CM, et al. Impact of HOTAIR Gene Polymorphism and Environmental Risk on Oral Cancer. J Dent Res 2018; 97: 717-724.

[9] Chou CH, Chou YE, Chuang CY, Yang SF, Lin CW. Combined effect of genetic polymorphisms of AURKA and environmental factors on oral cancer development in Taiwan. PLoS One 2017; 12: e0171583.

[10] Lin CW, Yang SF, Chuang CY, Lin HP, Hsin CH. Association of matrix metalloproteinase-11 polymorphisms with susceptibility and clinicopathologic characteristics for oral squamous cell carcinoma. Head Neck 2015; 37: 1425-1431.

[11] Su CW, Chien MH, Lin CW, Chen MK, Chow JM, Chuang CY, et al. Associations of genetic variations of the endothelial nitric oxide synthase gene 
and environmental carcinogens with oral cancer susceptibility and development. Nitric Oxide 2018; 79: 1-7.

[12] Su SC, Hsieh MJ, Liu YF, Chou YE, Lin CW, Yang SF. ADAMTS14 Gene Polymorphism and Environmental Risk in the Development of Oral Cancer. PLoS One 2016; 11: e0159585.

[13] Su CW, Chen MK, Hung WC, Yang SF, Chuang CY, Lin CW. Functional variant of CHI3L1 gene is associated with neck metastasis in oral cancer. Clin Oral Investig 2019; 23: 2685-2694.

[14] Su SC, Lin CW, Liu YF, Fan WL, Chen MK, Yu CP, et al. Exome Sequencing of Oral Squamous Cell Carcinoma Reveals Molecular Subgroups and Novel Therapeutic Opportunities. Theranostics 2017; 7: 1088-1099.

[15] Yang SF, Huang HD, Fan WL, Jong YJ, Chen MK, Huang CN, et al. Compositional and functional variations of oral microbiota associated with the mutational changes in oral cancer. Oral Oncol 2018; 77: 1-8.

[16] Mocellin S, Tropea S, Benna C, Rossi CR. Circadian pathway genetic variation and cancer risk: evidence from genome-wide association studies. BMC Med 2018; 16: 20.

[17] Morales-Santana S, Morell S, Leon J, Carazo-Gallego A, Jimenez-Lopez JC, Morell M. An Overview of the Polymorphisms of Circadian Genes Associated With Endocrine Cancer. Front Endocrinol (Lausanne) 2019; 10: 104.

[18] Hua KT, Liu YF, Hsu CL, Cheng TY, Yang CY, Chang JS, et al. 3'UTR polymorphisms of carbonic anhydrase IX determine the miR-34a targeting efficiency and prognosis of hepatocellular carcinoma. Sci Rep 2017; 7: 4466.

[19] Huang CH, Chen CI, Chen PN, Wang SS, Chou YE, Hung SC, et al. Impacts of AURKA Genetic Polymorphism on Urothelial Cell Carcinoma Development. J Cancer 2019; 10: 1370-1374.

[20] Lin CW, Yang WE, Lee WJ, Hua KT, Hsieh FK, Hsiao M, et al. Lipocalin 2 prevents oral cancer metastasis through carbonic anhydrase IX inhibition and is associated with favourable prognosis. Carcinogenesis 2016; 37: 712-722.

[21] Shridhar K, Aggarwal A, Walia GK, Gulati S, Geetha AV, Prabhakaran D, et al. Single nucleotide polymorphisms as markers of genetic susceptibility for oral potentially malignant disorders risk: Review of evidence to date. Oral Oncol 2016; 61: 146-151.

[22] Levran O, Peles E, Randesi M, Correa da Rosa J, Ott J, Rotrosen J, et al Dopaminergic pathway polymorphisms and heroin addiction: further support for association of CSNK1E variants. Pharmacogenomics 2014; 15: 2001-2009.

[23] Toyoshima M, Howie HL, Imakura M, Walsh RM, Annis JE, Chang AN, et al. Functional genomics identifies therapeutic targets for MYC-driven cancer. Proc Natl Acad Sci U S A 2012; 109: 9545-9550.

[24] Varghese RT, Young S, Pham L, Liang Y, Pridham KJ, Guo S, et al. Casein Kinase 1 Epsilon Regulates Glioblastoma Cell Survival. Sci Rep 2018; 8: 13621.

[25] Yang WS, Stockwell BR. Inhibition of casein kinase 1-epsilon induces cancer-cell-selective, PERIOD2-dependent growth arrest. Genome Biol 2008; 9: R92.

[26] Lin CW, Chen PN, Chen MK, Yang WE, Tang CH, Yang SF, et al. Kaempferol reduces matrix metalloproteinase-2 expression by down-regulating ERK1/2 and the activator protein-1 signaling pathways in oral cancer cells. PLoS One 2013; 8: e80883.

[27] Ray JG, Ganguly M, Rao BS, Mukherjee S, Mahato B, Chaudhuri K. Clinico-epidemiological profile of oral potentially malignant and malignant conditions among areca nut, tobacco and alcohol users in Eastern India: A hospital based study. J Oral Maxillofac Pathol 2013; 17: 45-50.

[28] Lopes CF, de Angelis BB, Prudente HM, de Souza BV, Cardoso SV, de Azambuja Ribeiro RI. Concomitant consumption of marijuana, alcohol and tobacco in oral squamous cell carcinoma development and progression: recent advances and challenges. Arch Oral Biol 2012; 57: 1026-1033. 